\title{
End-User Computing Satisfaction (EUCS) in Computerised Accounting System (CAS): Which the Critical Factors? A Case in Malaysia
}

\author{
Azleen Ilias \\ Mohd Zulkeflee Abd Razak \\ Rahida Abdul Rahman \\ Mohd Rushdan Yasoa' \\ School of International Business and Finance Labuan \\ Universiti Malaysia Sabah \\ Labuan International Campus \\ 87000 , F.T Labuan, Malaysia \\ Tel: 60-8746-0517Ｅ-mail: neelza80@yahoo.co.uk
}

\begin{abstract}
This paper is to examine critical factors; content, accuracy, format, ease of use, timeliness, satisfaction with system speed and system reliability in End-User Computing Satisfaction (EUCS) that influence most end-users' satisfaction. The research was conducted using a set of questionnaire consist of seven factors; content, accuracy, format, ease of use, timeliness, satisfaction with system speed and system reliability to measure end-users' satisfaction. In addition, this study covered 90 end-users of Computerised Accounting System (CAS) in finance department from 62 Responsibility Centres. This study is analyzed with reliability analysis, descriptive analysis and multiple regressions. Overall, this study indicates that most of end-users are almost satisfied with Computerised Accounting System (CAS). The results show that ease of use, content, and accuracy has a significant effect on end-users' satisfaction. Therefore, the empirical results of this study can provide support for the Doll and Torkzadeh model (1988), which related to the factors contributing end-users' satisfaction toward accounting system.
\end{abstract}

Keywords: End-User Computing Satisfaction, Computerised Accounting System, Multiple Regressions

\section{Introduction}

\subsection{Introduction}

Since the beginning of 1980s, many researches had conducted survey in information system field highlighting the tremendous development in end-user computing world. In fact, the growth of end-user computing is one of the significant phenomena of the 1980s in the information management world (David, 1983). A study by the International Data Corporation predicted that four out of five administrative and professional workers would be using personal computing to support their work and personal activities by 1990 .

In general practices, there are different between the practices in the public or government sectors and the business/private companies. Hence, the applications of the Computerised Accounting System (CAS) in these organisations also differ from one to another. For instance, the private organisation utilizes the general ledger system and the accounting principles based on accrual basis. However, the public organisations employ vote accounting system, which is based on cash basis. The financial management of the organisation is also related to budgeting using a code and warrant system (Statutory Bodies Act 1980 (Account and Annual Report) (Act 240)). Thus, it seems to be interesting to investigate the level of satisfaction among end-user computing in government sector, since it is different compared to the company or business organisation.

Most of the end-user claimed that they are not satisfied with the Computerised Accounting System (CAS) which it was using in the government sector office. The previous study showed that the main factor contributing to dissatisfaction 
because of the limitation of stand-alone system among the various accountant general departments. Furthermore, it seems clear that a study on End-User Computing Satisfaction (EUCS) in Malaysia is best described as limited especially in government sectors. Therefore, the scarcity of empirical research in the area of end user satisfaction among Computerised Accounting System (CAS); especially in the Malaysian context is significant to this research.

Perhaps, having a good financial or computerised accounting information system will increase the performance of an organisation. Eventually, this enables the organisation to increase revenue in order to follow the recommendation of self-financing by the ministry. Therefore, the objective of the study is merely to examine the most critical factor that influences End-User Computing Satisfaction (EUCS) towards Computerised Accounting System (CAS).

The remainder of this paper is organized as follows. A review of related literature on end-users computing satisfaction and hypotheses is discussed. Next, the methodology employed in this study, research instruments used and data analysis method involved are described. Finally, the empirical results and discussion of the study are drawn.

\subsection{Research Objective}

1) To examine critical factors of content in End-User Computing Satisfaction (EUCS) that influence most end-users' satisfaction.

2) To examine critical factors of accuracy in End-User Computing Satisfaction (EUCS) that influence most end-users' satisfaction.

3) To examine critical factors of format in End-User Computing Satisfaction (EUCS) that influence most end-users' satisfaction.

4) To examine critical factors of ease of use in End-User Computing Satisfaction (EUCS) that influence most end-users' satisfaction.

5) To examine critical factors of timeliness in End-User Computing Satisfaction (EUCS) that influence most end-users' satisfaction.

6) To examine critical factors of system speed in End-User Computing Satisfaction (EUCS) that influence most end-users' satisfaction.

7) To examine critical factors of system reliability in End-User Computing Satisfaction (EUCS) that influence most end-users' satisfaction.

\section{Literature review}

\subsection{Literature review}

Unlike the other researchers, Pather et al. (2003) argued that the advent of e-Commerce has shifted the location of the traditional user of Information Systems out of the physical domain of the organisation or business. E-commerce businesses now have to deal with a new type of user viz. the e-Customer. Thus, they disputed that established instruments that measure user satisfaction of IS in traditional (brick and mortar) businesses are not completely appropriate. The authors, building on a comprehensive literature study, derived an appropriate model for exploring the measurement of e-customer satisfaction in the South African context.

Markovic \& Wood (2004) addressed the issue of user satisfaction with a computer lab in a university. Both formal and informal data gathering techniques were used to provide comprehensive data for this research. Data was gathered from both users and managers in order to provide a complete picture of the current situation. This data led to a research study of user satisfaction among students and support staff. The research revealed that satisfaction with hours and software and hardware performance had the greatest impact on user satisfaction followed closely by quality of support staff.

Bengts (2004) studies usability as a constituent of end- user computing satisfaction. Different measurement instruments and rating scales for user satisfaction have been created; however, the relationship between satisfaction and usability remains unclear. A web-based system with three different user interface alternatives was implemented and the system was used by information technology students to practice SQL-queries in a university course. 43 students reported their preference and the underlying reasons by answering both structured and open-ended questions in a web-based questionnaire. The results also indicated that availability of desired features, simple interaction and user-control are as constituents of satisfaction more important than simple screen design and error- free usage.

Huang et al. (2004) argued that while end-user computing satisfaction has been studied extensively, new aspects such as purchasing convenience, product prices in the system and product delivery have to be included. In their study, they developed an instrument for reliably and accurately measuring business-to-employee success. Test-retest reliability and construct validity were examined. Finally, they concluded that convenience, delivery, interface, accuracy, price and security influence employee assessments of satisfaction. Managers can use the instrument developed in their study to assess the success of their business-to-employee systems. 
This study is continuing from Azleen et al. (2007) that measured the level of satisfaction among the end users of CAS in Labuan F.T government sectors and also determine the relationship of seven factors (content, accuracy, format, ease of use, timeliness, satisfaction with system speed, system reliability) that influence satisfactory level among the end users toward the CAS. Furthermore, Azleen et al. (2007) also measured the level of EUCS among CAS end users in private companies. They evaluated the significant relationship between EUCS factors and the overall EUCS in Malaysian context and examined the differences of perception on overall EUCS among the demographic variables. This study found that EUCS factors more reliable as compared to previous studies and the correlation between satisfaction and EUCS factors are fairly strong. However, the study failed to detect significant differences of perception on overall EUCS on gender, level of education and position.

The scope of the discussion is related to EUCS; the previous factors that contribute to EUCS, Doll and Torkzadeh Model (1988); i.e., content, accuracy, format, ease of use, and timeliness and the modification made by Chin and Lee (2000), i.e. satisfaction with system speed, and system reliability (self developed). The model will become the fundamental guidelines to examine factors contributing to EUCS among Accountant General Department.

\subsection{Research Hypotheses}

The hypothesis of overall End-User Computing Satisfaction (EUCS) is constructed based on seven factors: (1) content (2) accuracy (3) format (4) ease of use (5) timeliness (6) satisfaction with system speed and (7) system reliability. These seven factors measure is formulated to test the relationship with the overall End-User Computing Satisfaction (EUCS) that more focused questions, aimed specifically on CAS. Thus, the hypotheses for this study are summarized as follows:

H1: There is significant effect between content and end-users' satisfaction towards Computerised Accounting System (CAS)

H2: There is significant effect between accuracy and end-users' satisfaction towards Computerised Accounting System (CAS).

H3: There is significant effect between format and end-users' satisfaction towards Computerised Accounting System (CAS).

H4: There is significant effect between ease of use and end-users' satisfaction towards Computerised Accounting System (CAS).

H5: There is significant effect between timeliness and end-users' satisfaction towards Computerised Accounting System (CAS).

H6: There is significant effect between system speed and end-users' satisfaction towards Computerised Accounting System (CAS).

H7: There is significant effect between system reliability and end-users' satisfaction towards Computerised Accounting System (CAS).

\section{Research Methodology}

\subsection{Sampling and Instrumentation}

This study relies on survey design as it deemed more appropriate compared with other designs of research in order to achieve the objective of the study. The population of this study covered the end users of Computerised Accounting System (CAS) in each Responsibility Centres in East Malaysia. Responsibility Centres known as government agencies that responsible to manage and control financial management in order to collect and report revenue and cost information by areas of responsibility. However, only 62 Responsibility Centres were chosen due to time and cost limitation. We have distributed two questionnaires for each department and the total population are 124 respondents. Sekaran, U. (2003) has stated that the sample should be taken for this population are 97 respondents. Nevertheless, only 90 respondents have completed and submitted these questionnaires.

Basically, the instrument of this study is based on the instruments, which was developed by Chin and Lee (2000). It presents a new set instrument while focusing on the same five construct domains. They are: content, accuracy, format, ease of use, and timeliness (Doll \& Torkzadeh, 1988); and satisfaction with system speed (Chin \& Lee, 2000). According to their findings, the relationship between the overall measures of satisfaction than the baseline model is expected to be relatively strong.

\subsection{Data Analysis Method}

To analyse the data, this study conducts descriptive analysis and multiple regression analysis using the SPSS 13.0 (statistical package for social science) software for windows. The study also tested reliability of the instrument so that it enables to produce a robust and valid result. 


\section{Data Analysis and Results}

\subsection{Reliability Analysis}

Table 1 summarizes the reliability analysis for each items and satisfaction. Each items show above 0.7 . It seems that this study provides more reliable instruments because most of the score is higher than Doll and Torkzadeh (1988). The content score in Doll and Torkzadeh (1988)'s study is 0.89 as compared to 0.918 in this study; accuracy=0.91 (0.875); format $=0.78(0.927)$; ease of use $=0.85(0.927)$; timeliness $=0.82(0.751)$. The coefficient alpha for system speed is higher (0.800) than Chin and Lee study (0.72) and system reliability is a new factor provides 0.759 and presents a reliable dimension for EUCS measurement. The reliability of the instruments of the study can be compared with Amdan et al (2006). From the table, only system reliability and ease of use show better than Amdan et al (2006).

\subsection{Descriptive Statistics}

The results of the descriptive analysis are shown in Table 2. From the result, the highest mean is satisfaction with the format (3.69) and the lowest mean is timeliness (3.34). It seems like most of the staff satisfied with format factor and less satisfied with timeliness factor. The highest standard deviation is ease of use (0.69) and the lowest is system reliability (0.56). The ease of use is deviate too far from the mean and system reliability is too close to the mean.

\subsection{Multiple Regressions}

Multiple regression analysis was performed in analysing the data. Properties of casual paths, including standardised coefficients beta, $t$ values and significant results, for each equation in the hypothesized model, are presented in Table 5. Table 3 presents the result of model summary that system reliability, timeliness, format, accuracy, content, ease of use and system speed predict the end-users satisfaction towards computerized accounting system (CAS) usage. From this model, R represents the simple correlation .922 and R Square is .850 , which shows that $85 \%$ changes in satisfaction can be explained by system reliability, timeliness, format, accuracy, content, ease of use and system speed. However, $15 \%$ changes can also be explained by other variables that influence the level of satisfaction. The result of the Adjusted $\mathrm{R}$ Square tested shows that system reliability, timeliness, format, accuracy, content, ease of use and system speed contribute significantly $(\mathrm{F}=66.564 ; \mathrm{P}<.001)$ as shown in Table 4 and predict $83.8 \%$ of variation in end-users' satisfaction.

\subsection{Discussion}

The results show that Hypothesis 1, Hypothesis 2 and Hypothesis 4 has significant effect with end-users' satisfaction. The significant relationship was found between ease of use and end-users' satisfaction towards computerized accounting system (CAS), $(\beta=.280, t=3.501, \mathrm{p}=.001)$. This factor will be the most critical factor that contribute in end-users' satisfaction and it seems that users need to have accounting system that easy to be understood and handled according to the structured module. This result has support to accept Hypothesis 1. Next, null hypothesis for Hypothesis 2 is rejected because second most critical factor is between content of accounting system and satisfaction based on the findings $(\beta=.216, t=2.702, p=.0080)$ is revealed. This is because most of the end-users satisfied with the content of accounting system. The last factor that contribute to the satisfaction is accuracy of accounting system $(\beta=.183, \mathrm{t}=2.088$, $\mathrm{p}=.040$ ) and Hypothesis 4 is substantiated. Most likely this circumstance is contributed by the high quality of accounting information.

Furthermore, Hypothesis 3, Hypothesis 5, Hypothesis 6 and Hypothesis 7 are also constructed to examine the significant effect with end-users' satisfaction. Hypothesis 3 avers that format of the accounting system has significant effect on end-users' satisfaction. Table 3 illustrates that the effect of format of the system on end-users' satisfaction was not substantiated $(\beta=.087, \mathrm{t}=1.120, \mathrm{p}=.266)$. Next, Hypothesis 5 asserts that timeliness has significant effect on end-users' satisfaction. However, table 3 shows that the timeliness has insignificant effect with end-users' satisfaction and null hypothesis is accepted $(\beta=.105, \mathrm{t}=1.740, \mathrm{p}=.086)$. Further, null hypothesis for Hypothesis 6 is accepted according to the result in table $3(\beta=.125, \mathrm{t}=1.538, \mathrm{p}=.128)$. The factor of system speed also do not effect significantly to end-users' satisfaction. It seems not important to influence the usability and emotional responses among users. Finally, the hypothesis regarding reliability of accounting system has significant effect on end-users' satisfaction (Hypothesis 7) was not confirmed $(\beta=.087, \mathrm{t}=1.120, \mathrm{p}=.266)$. Undoubtedly, some of end-users are not aware with accounting system security or privacy. This is because most of accounting system in government sector is supervised by information technology unit or department. Thus, most of end users only intend to use and utilize this system regardless the reliability of its security system.

\section{Conclusion}

This research attempted to measure the end-users satisfaction of CAS using multiple regression by determine the significant effect of seven factors that influence end users' satisfaction. Overall, this study indicates that most of end users are almost satisfied with the CAS. It can be explained by descriptive statistics result which indicates high satisfaction for each of EUCS factors. In addition, this study has enabled to identify the most critical factor that 
influences end-user computing satisfaction towards CAS. The results show that ease of use, content, and accuracy has a significant effect on end-users satisfaction. In other words, the usability of CAS is enormously important in producing accurate output or content of CAS.

\section{Implications and future research}

The study demonstrated the EUCS factors in the government sectors with the CAS. The study also suggests that content, accuracy, format, ease of use, timeliness, satisfaction with system speed and system reliability must be emphasized to the standardized CAS. However, software developers must emphasize the user friendly and usability of the system which might generate better output especially in terms of accuracy of the content.

The finding of this study is preliminary and shall not be generalized to the other government sectors. This is due to the different in the adoption of the information technology and CAS especially in information system usage. Besides, the number of the sample is relatively small. The small sample size is limited only 90 end-users of CAS. This small sample size may be jeopardizing the population of the end user among the government sectors. The aspect of time also affected the data collection method; i.e., by using questionnaire. A respondent who is not particularly interested in answering the questionnaire is more likely interspersed to answer the question. This is because some of them are very busy with their tasks and duties. As a result, they did not answer the questionnaire genuinely.

The future study can propose the other data collection method such as in depth interview with the end user computing. In this study, questionnaire has been used to collect the data through owing to the fact that financial and time are of the essence. The sample size should also be increased. A larger sample size would be required to ensure that the generalisation ability of research. The future research should also consider the type of software, whether the department purchases or develops the system. It is essential to measure the different perception on the overall EUCS among these two types of the system since the end users are expected to have a different level of satisfaction.

\section{References}

Amdan, M., Rushdan, M.Y., Azleen, I., \& Fahmi, M.G. (2006). The study of end-users computing satisfaction (EUCS) on computerised accounting system (CAS) among peninsular Malaysia public universities: A survey in bursar's office. Proceedings of International Borneo Business Conference 2006. 2, 594-608.

Azleen., I., Mohd Rushdan,Y., Mohd Zulkeflee,A.R., Rahida., A.R. . (2007). The Study Of End-user Computing Satisfction (EUCS) On Computerised Accounting System (CAS) Among Labuan F.T Government Sectors: A Case Study In The Responsibility Centres. Labuan E-journal Of Muamalat And Society. vol.1: 1-14.

Azleen, I., Mohd Rushdan, Y.,. \& Mohd Zulkeflee, R., \& Rahida, A.R. (2007). The Study Of End-User Computing Satisfaction (EUCS) On Computerised Accounting System (CAS) Among Labuan F.T Private Companies. International Management Accounting Conference IV. 15-17 August 2007, Kuala Lumpur, pp. 1-17, ISBN: 978-983-3198-11-5.

Bengts, M. (2004). Usability as a constituent of end-user computing satisfaction, Department of Computer Science and Information Systems, University of Jyväskylä. Unpublished Master Thesis.

Chin, W.W., \& Lee, M. K. O. (2000). A proposed model and measurement instrument for the formation of is satisfaction: The case of end-user computing satisfaction. Proceedings of The Twenty First International Conference On Information Systems. 175-186.

David, H.B. (1983). A field study of end-user computing: Findings and issues. MIS Quarterly, 7(4), 34-47.

Doll, W. J., \& Torkzadeh, G. (1988). The measurement of end-user computing satisfaction. MIS Quarterly. 12(6), 259-274.

Huang, J.H., Yang, C., Jin, B.H, \& Chiu, H. (2004). Measuring satisfaction with business-to employee systems, Computers in Human Behavior 20, pp.17-35.

Markovic, B. \& Wood, J. (2004). User satisfaction with CBA computer labs, CCSC: South Central Conference, pp 232-239.

Pather, S., Erwin, G., \& Remenyi, D. (2003). Measuring e-commerce effectiveness: A conceptual model, Proceedings of SAICSIT 2003, Pp. 143-152.

Sekaran, U. (2000). Research method for business - A skill building approach, $\left(3^{\mathrm{rd}}\right)$ Edition, John Wiley \& Sons.

Statutory Bodies Act 1980 (Account and Annual Report) (Act 240) 


\section{Notes}

Table 1. Reliability Analysis

\begin{tabular}{|l|c|c|c|c|}
\hline \multirow{3}{*}{ Variable } & $\begin{array}{c}\text { Alpha } \\
\text { (Coefficient) }\end{array}$ & $\begin{array}{c}\text { Alpha } \\
\text { (Coefficient) }\end{array}$ & $\begin{array}{c}\text { Alpha } \\
\text { (Coefficient) }\end{array}$ & $\begin{array}{c}\text { Alpha } \\
\text { (Coefficient) }\end{array}$ \\
\cline { 2 - 5 } & Current study & $\begin{array}{c}\text { Doll and Torkzadeh } \\
(1988)\end{array}$ & $\begin{array}{c}\text { Chin and Lee } \\
(2000)\end{array}$ & $\begin{array}{c}\text { Amdan et al. } \\
(2006)\end{array}$ \\
\hline Satisfaction (DV) & 0.771 & - & - & 0.8550 \\
\hline Content & 0.918 & 0.89 & - & 0.9243 \\
\hline Accuracy & 0.875 & 0.91 & - & 0.8834 \\
\hline Format & 0.927 & 0.78 & - & 0.9256 \\
\hline Ease of Use & 0.927 & 0.85 & - & 0.8912 \\
\hline Timeliness & 0.751 & 0.82 & - & 0.8711 \\
\hline System Speed & 0.800 & - & 0.72 & 0.9126 \\
\hline System Reliability & 0.759 & - & - & 0.7204 \\
\hline
\end{tabular}

Table 2. Descriptive Analysis

\begin{tabular}{|l|c|c|c|c|c|}
\hline \multicolumn{1}{|c|}{$\mathrm{N}$} & Minimum & \multicolumn{2}{|c|}{ Maximum } & Mean & Std. Deviation \\
\hline Content & 90 & 2.33 & 5.00 & 3.76 & .58 \\
\hline Accuracy & 90 & 2.43 & 5.00 & 3.55 & .59 \\
\hline Format & 90 & 2.43 & 5.00 & 3.69 & .68 \\
\hline Ease of Use & 90 & 2.14 & 5.00 & 3.60 & .69 \\
\hline Timeliness & 90 & 2.50 & 5.00 & 3.34 & .59 \\
\hline System Speed & 90 & 2.33 & 4.83 & 3.48 & .56 \\
\hline System Reliability & 90 & 2.29 & 4.71 & 3.49 & .57 \\
\hline Satisfaction (Dependent Variable) & 90 & 2.14 & 5.00 & 3.61 & .63 \\
\hline Valid N (listwise) & & \multicolumn{5}{|c}{90} \\
\hline
\end{tabular}

Table 3. Model Summary

\begin{tabular}{cccc}
\hline Model & $\mathrm{R}$ & $\mathrm{R}$ Square & Adjusted R Square \\
\hline 1 & .922 & .850 & .838 \\
\hline
\end{tabular}

a. Predictors: (Constant), System reliability, Timeliness, Format, Accuracy, Content, Ease of Use and System Speed b. Dependent Variable: Satisfaction

Table 4. ANOVA

\begin{tabular}{ccccccc}
\hline Model & & Sum of & df & Mean & F & Sig. \\
& & Squares & & Square & & \\
\hline 1 & Regression & 30.274 & 7 & 4.325 & 66.564 & .000 \\
& Residual & 5.328 & 82 & .065 & & \\
& Total & 35.602 & 89 & & & \\
\hline
\end{tabular}

a. Predictors: (Constant), System reliability, Timeliness, Format, Accuracy, Content, Ease of Use and System Speed

b. Dependent Variable: Satisfaction 
Table 5. Coefficients between EUCS factors and end-users' satisfaction towards Computerised Accounting System (CAS)

\begin{tabular}{|c|c|c|c|c|}
\hline \multicolumn{5}{|c|}{ Coefficients } \\
\hline Model & & Beta & & \\
\hline \multirow[t]{8}{*}{1} & (Constant) & & -1.991 & .050 \\
\hline & EASE & $.280 * *$ & 3.501 & .001 \\
\hline & CONTENT & $.216^{* *}$ & 2.702 & .008 \\
\hline & ACCURACY & $.183^{* *}$ & 2.088 & .040 \\
\hline & TIME & .105 & 1.740 & .086 \\
\hline & SPEED & .125 & 1.538 & .128 \\
\hline & RELIABLE & .095 & 1.392 & .168 \\
\hline & FORMAT & .087 & 1.120 & .266 \\
\hline
\end{tabular}

a. Dependent Variable: Satisfaction

** Significant at the 0.05 level (2-tailed). 